\title{
Simulation study of oxygen-enriched cylinder combustion in the zero emissions internal combustion engine
}

\author{
Yan Shi $^{a}$, Yongfeng LIU ${ }^{\text {b* }}$, Shengzhuo Yao ${ }^{\mathrm{c}}$ \\ Beijing Research Centre of Sustainable Energy and Building, Beijing University of Civil Engineering \\ and Architecture, 100044 Beijing, China \\ asyst1988@163.com, bliuyongfeng@bucea.edu.cn, cyaoshengzhuo@bucea.edu.cn
}

Keywords: Zero emissions; Oxygen-enriched combustion; Numerical simulation; $\mathrm{CO}_{2}$ fixation

\begin{abstract}
In order to get the best inlet concentration of the $\mathrm{O}_{2} / \mathrm{CO}_{2}$ mixture oxygen-enriched combustion in the internal combustion engine, and to improve oxygen-enriched combustion efficiency, this article uses KIVA-3V software, with the former processing program K3PREP and Iprep document which includes all the information of modeling, to complete combustion modeling and generate the burning space grid. Though $k-\varepsilon$ turbulence model, we got the spray and burning process simulation, and then draw the peak curve of peak temperature and pressure under the different intake concentration of $\mathrm{O}_{2} / \mathrm{CO}_{2}$ mixture air in the internal combustion engine. In this article, it shows the result that the best inlet concentration of the mixture of $\mathrm{O}_{2} / \mathrm{CO}_{2}$ oxygen-enriched combustion in the internal combustion engine is $24 \%$ through the further analysis of the data. Because the pressure and temperature in advance rate, we should take off ignition time, so as to achieve the best combustion characteristics.
\end{abstract}

\section{Introduction}

In today's world, with the industrial development, the first consideration is environmental sustainability, as far as possible to achieve energy conservation. As the Automobile industry is booming in China, new engines which can meet the requirements of energy saving and environmental protection is bound to become the focus of research. Oxygen-enriched combustion of internal combustion engine is one of the main ways of energy saving. Oxygen-enriched combustion can increase the fuel combustion in calorific value, heat efficiency and work capacity, comparing with ordinary air combustion with the same quality ${ }^{[1]}$. At the same time, the theoretical calculation proved that the oxygen-enriched combustion can eliminate the generation of $\mathrm{CH}, \mathrm{CO}$ and other pollutants. Due to ordinary air contains nitrogen, which can produce $\mathrm{CO}_{2}$ and $\mathrm{NOx}$ pollutants when it burns with hydrocarbon fuels. It is researched in this paper that the internal combustion engine solidified $\mathrm{CO}_{2}$ with liquid oxygen and burned with liquid oxygen. The new method can completely solve the problem of the produce of $\mathrm{CO}_{2}$ and $\mathrm{NOx}$ pollutants and the mode of exhaust gas recirculation could reduce the pollutants emissions of $\mathrm{CH}$ and $\mathrm{NO}_{\mathrm{x}}{ }^{[2]}$.

Robert W. Bilger et $\mathrm{al}^{[3-5]}$ analyzed theoretically the feasibility of the Rankine cycle internal combustion engine, and got that the Rankine cycle is more efficient from the cycle theory, and found that the internal combustion engine using Rankine cycle (ICRC) need to consume the cost of liquid oxygen, however, the accounting of $\mathrm{CO}_{2}$ savings fixed by the ICRC cycle and the fuels reduced using the Rankine cycle engine is economic better than the ordinary engines from the perspective of economic analysis.

\section{System principle}

In this study, the overall program is shown in Figure 1. Exhaust gas produced when the internal combustion engine startup goes through the exhaust pipe into $\mathrm{CO}_{2}$ capture device. The liquid oxygen in liquid oxygen storage tank enters the same $\mathrm{CO}_{2}$ capture device through liquid oxygen tube. 
Through the heat transfer of phase change between mixed gases, liquid oxygen vaporized into oxygen, and discharged from the $\mathrm{CO}_{2}$ capture device, and went into the pressure device of intake tube through the internal combustion engine intake tube to increase the pressure, and enter the internal combustion engine. Combustion exhaust gas $\mathrm{CO}_{2}$ enters into the condensing water set which is covered on the exhaust gas tube of internal combustion engine and the temperature gets down to close to $40^{\circ} \mathrm{C}$. Then other part of the exhaust gas $\mathrm{CO}_{2}$ entered into the EGR pipe, and mixed with the vaporized oxygen. The mixture, which combusted in the internal combustion engine is mixed in the ratio which can slow down the excessive oxygen combustion speed. Another part of the exhaust gas $\mathrm{CO}_{2}$ went into the capture device, and transferred heat in the phase change way with liquid oxygen. At this point, liquid oxygen is vaporized into oxygen, and exhaust gas $\mathrm{CO}_{2}$ all been condensed and became dry ice. It got out of the $\mathrm{CO}_{2}$ capture device through the dry ice collection tube at the bottom of the $\mathrm{CO}_{2}$ capture device, finally reached the dry ice seal device, so that $\mathrm{CO}_{2}$ fixation and zero emissions combustion could achieved by the internal combustion engine.

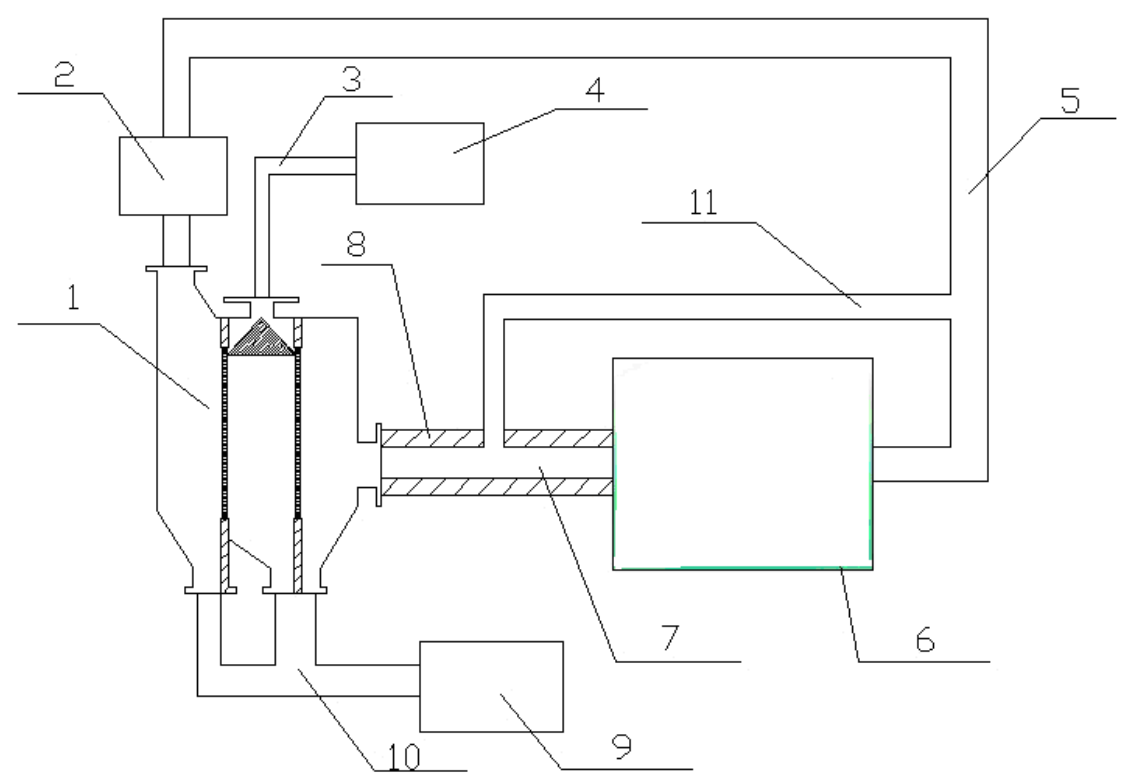

Fig. 1 The overall program plan

1- $\mathrm{CO}_{2}$ capture device, 2 - pressure device of intake tube, 3 - liquid oxygen tube, 4 - liquid oxygen storage tank, 5 - internal combustion engine intake tube, 6 - the internal combustion engine, 7 exhaust pipe, 8 - condensing water set, 9 - dry ice storage device, 10 - dry ice collection tube,11-the EGR tube.

The advantages of the oxygen-enriched combustion system described in this article compared with the Rankine cycle system. ${ }^{[6-7]}$ : Firstly, the Rankine cycle system used water spray into the cylinder to reduce oxygen combustion speed, thus the system is more complicated and the cylinder head production is more complicated because the sprinkler system needs the water jet in the cylinder head. Secondly, this system described in the paper uses the recycling exhaust $\mathrm{CO}_{2}$ and vaporized oxygen to burn together in the internal combustion engine, which can both to solve the problem of pure oxygen combustion is too fast, but also to achieve zero emissions of internal combustion engines. Thirdly, the $\mathrm{CO}_{2}$ fixation device, which uses a hybrid heat exchanger, has higher heat transfer efficiency than the Rankine cycle system which fixed $\mathrm{CO}_{2}$ with a partitions heat exchanger. 


\section{Calculation results and analysis}

\section{Numerical calculation.}

a. Momentum conservation equation

$$
\begin{aligned}
& \frac{\partial(\rho \boldsymbol{u})}{\partial t}+\nabla \cdot(\rho \boldsymbol{u} \boldsymbol{u})=-\frac{1}{a^{2}} \nabla p \\
& -A_{0} \nabla\left(\frac{2}{3} \rho k\right)+\nabla \cdot \sigma+F^{s}+\rho g
\end{aligned}
$$

In the equation:

$a$ Dimensionless constant, related to the Pressure Gradient Scaling (PGS) method. The PGS method is used to strengthen the flow of low Mach number computational efficiency. In this article $\mathrm{a}=1$.

$F^{s}$ _ Spray oil particles passed to the fluid momentum per unit volume per unit time.

$\mathrm{A}_{0} \longrightarrow$ is 1 as used the turbulence calculation.

b. Energy conservation equation

The form of the partial differential equations is

$$
\begin{aligned}
& \frac{\partial(\rho I)}{\partial t}+\nabla \cdot(\rho \boldsymbol{u} I)=-p \nabla \cdot \boldsymbol{u} \\
& +\left(1-A_{0}\right) \sigma \nabla \boldsymbol{u}-\nabla \cdot \boldsymbol{J}+A_{0} \rho \varepsilon+Q^{c}+Q^{s}
\end{aligned}
$$

Where, I — the internal energy of the fluid (Does not include the chemical reaction energy) $(\mathrm{J} / \mathrm{kg})$.

$\mathrm{J}-$ Heat flux vector.

$Q^{c} \_$chemical heat release rate $(\mathrm{J} / \mathrm{s})$.

$Q^{s} \_$Spray oil particles interaction with the fluid source term.

$$
\dot{Q^{c}}=\sum_{r} Q_{r} \dot{\varpi}_{r}
$$

Where, $Q_{r}$ the negative reaction heat of Absolute zero ( $\left.\mathrm{J}\right)$.

$$
Q_{r}=\sum_{m}\left(a_{m r}-b_{m r}\right)\left(\Delta h_{f}^{0}\right)_{m}
$$

The heat flux is determined by:

$$
\boldsymbol{J}=-k \nabla T-\rho D \sum_{m} h_{m} \nabla\left(\rho_{m} / \rho\right)
$$

Where, $\mathrm{k} \longrightarrow$ thermal conductivity.

$\mathrm{T}$ — thermodynamic temperature of the fluid $(\mathrm{K})$.

$h_{m}$ the enthalpy of chemical components $\mathrm{m}(\mathrm{J})$.

This article completed the combustion chamber modeling using K3PREP which is pre-treatment procedures of KIVA-3V. Iprep file contains all the information in the modeling and mesh the 
combustion space. Draw the peak temperature curve of the combustion with different concentrations of oxygen in Figure 2 by setting up the $k-\varepsilon$ turbulence model to simulate the spray and combustion process. Combustion temperature reaches a minimum value is $2550 \mathrm{~K}$ when the concentrations of oxygen is $23.5 \%$. Then the temperature continued to show an upward trend, and when the oxygen content is $42 \%$, the temperature reached the highest value which is $2775 \mathrm{~K}$. With the increase of the oxygen content, the fuel burns more completely, so the temperature peak is higher. At the same time the fuels burning faster, the time of the peak temperature appears faster. When the oxygen content is $23 \%$, the temperature reaches a minimum value due to the fuels' incomplete burning.

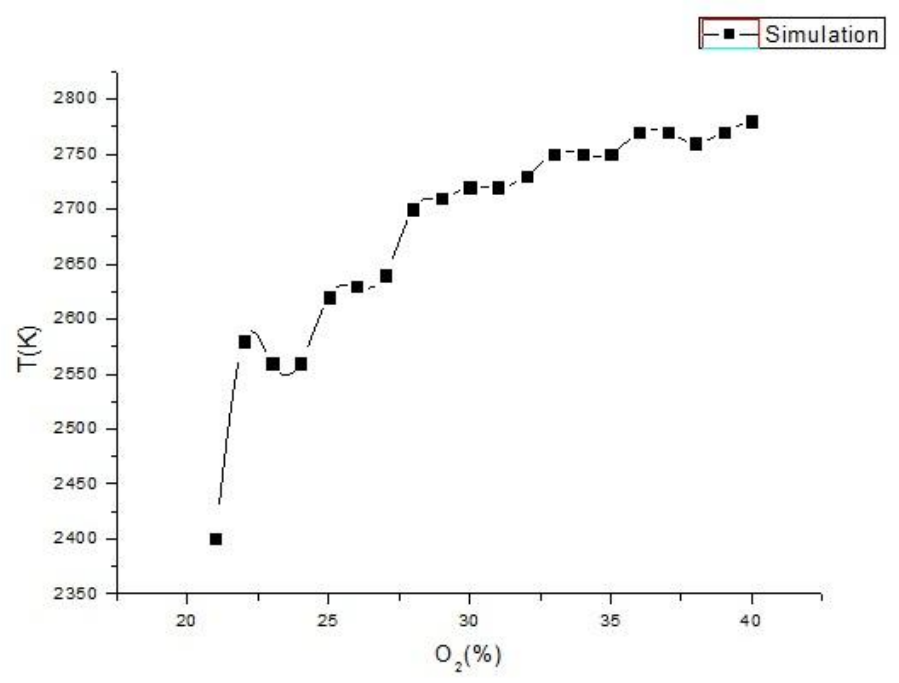

Fig. 2 the peak temperature curve

\section{Conclusions}

(1) Considering the peak pressure and the peak temperature, oxygen concentration of $24 \%$, can make the combustion pressure rise rate increase, and the heat release rate increase, at the same time, the lowest rate of combustion cycle change in the internal combustion engine, and got the maximum power capability of the internal combustion engine.

(2) As a result of the peak combustion temperature and the peak pressure crank angle in advance when the oxygen concentration of the oxygen-enrich combustion is $24 \%$, we got that if the engine used the oxygen-rich combustion and the measure of delaying the ignition advance angle in conjunction, it can achieve the desired combustion characteristics.

\section{Acknowledgements}

The study was sponsored by The Importation and Development of High-Caliber Talents Project of Beijing Municipal Institutions ( CIT\&TCD20140311) and Beijing Natural Science Fund (SQKZ201510016004).

\section{References}

[1] Zhang Wei, Shu Gequn, Shen Yinggang, Zhao Wei, Liang Youcai. Simulation of Diesel Engine Fueled with Different Water-emulsion Rates and Different Oxygen Concentrations in Intake Air[J]. Transactions of the Chinese Society for Agricultural Machinery, 2011.9, 42(9), 1-7. 
[2] PeterL. Perez et al. Experimental study on combustion in oxygen-enriched diesel engine with EGR[J]. Foreign Diesel Locomotive, 2010, 4(412): 14-23.

[3] Robert W. Bilger, Zhijun Wu. Carbon Capture for Automobiles Using Internal Combustion Rankine Cycle Engines[J]. Journal of Engineering for Gas Turbines and Power, 2009.5, 31: 034502 .

[4] Li Shengqin, Guan Qiang. Study of the Interior Process of Oxygen-enriched Combustion on Mini-type Gasoline Engine[J]. Small Internal Combustion Engine and Motorcycle, 2008.4, 37(2): 22-26.

[5] R.R.Sekar, W.W.Marr, D.N.Assanis, R.L.Cole, T.J.Marciniak, J.E.Schaus. Oxygen-Enriched Diesel Engine Perfoumance: A Compasion of Analytical and Experimental Results[J]. Journal of Engineering for Gas Turbines and Power, 1991.7, 113: 365-369.

[6] Xiao Fu, Suresh K. Aggarwal,Two-stage ignition and NTC phenomenon in diesel engines,Fuel, [J].2015,144 (3):188-196

[7] H.An,W.Yang,J.Li,D.Zhou,Modeling study of oxygenated fuels on diesel combustion:Effects of oxygen concentration,cetane number and $\mathrm{C} / \mathrm{H}$ ratio,Energy Conversion and Management,2015,90(1):261-271

[8] Hanyu Chen,ChengjiZuo,Haichun Ding,ZuofengWang,Duidui Wang,Numerical simulation on combustion processes of a diesel engine under O2/CO2 atmosphere, HKIE Transactions,2013,20(3):157-163

[9] X.Yu, Z.Wu, L. Fu, J.Deng,Study of combustion characteristics of a quasi internal combustion rankine cycle engine, SAE Technical Paper 2013012698

[10] H.An,W.Yang,J.Li,D.Zhou,Modeling study of oxygenated fuels on diesel combustion:Effects of oxygen concentration,cetane number and $\mathrm{C} / \mathrm{H}$ ratio,Energy Conversion and Management,2015,90(1):261-271 